EMBRYARIDDLE
Aeronautical University

SCHOLARLY COMMONS

\section{International Journal of Aviation,} Aeronautics, and Aerospace

6-13-2018

\title{
Personality Types and Learning Styles of Collegiate Aviation Students
}

\author{
Stephanie Fussell \\ Embry-Riddle Aeronautical University, sfussel2@kent.edu \\ Andrew R. Dattel \\ Embry-Riddle Aeronautical University, andy.dattel@erau.edu \\ Kadie Mullins \\ Embry-Riddle Aeronautical University, haywardk@erau.edu
}

Follow this and additional works at: https://commons.erau.edu/ijaaa

Part of the Curriculum and Instruction Commons, Personality and Social Contexts Commons, and the Scholarship of Teaching and Learning Commons

\section{Scholarly Commons Citation}

Fussell, S., Dattel, A. R., \& Mullins, K. (2018). Personality Types and Learning Styles of Collegiate Aviation Students. International Journal of Aviation, Aeronautics, and Aerospace, 5(3). https://doi.org/10.15394/ ijaaa.2018.1223

This Article is brought to you for free and open access by the Journals at Scholarly Commons. It has been accepted for inclusion in International Journal of Aviation, Aeronautics, and Aerospace by an authorized administrator of Scholarly Commons. For more information, please contact commons@erau.edu. 
It is essential to understand the role learning styles play in education. Understanding the relationship between student personality and learning styles can lead to more efficient and effective curricula design for aviation education programs and flight training. Wiggins (1998) assessed personality types, using the Myers-Briggs Type Indicator (MBTI), and attitudes toward teaching methods of students enrolled in a professional pilot program. The current study is a partial replication of the Wiggins study that examines the relationship of aviation student personality types, also using the MBTI. However, learning styles were assessed using the Kolb Learning Style Inventory (KLSI) as opposed to attitudes toward teaching methods. The study compared the distribution of MBTI types of students to the traditional college population, the distribution of MBTI types of students to the distribution of the MBTI types of students found by Wiggins (1998). The distribution of the KLSI preferences to students found in the traditional college population, and the distribution of the MBTI types and KLSI preferences by class standing. These comparisons tested if personality type is a predictive factor of aviation student learning preference.

There are many ways to learn, and the traditional lecture method often found in higher education and training environments may not be the most effective method of teaching the subject matter to aviation students. Use of learning style and individualized teaching could improve learner satisfaction and achievement (Cronbach \& Snow, 1969). Recognizing the learning preferences of students allows an instructor to adapt lesson plans to student strengths. Teaching to multiple learning styles challenges students to learn in multiple ways and prepares them for a professional world that will not always cater to their needs (Felder \& Brent, 2005). The goal, then, is adopting a balanced approach that allows the instructor to accommodate the needs of the students while ensuring course objectives are met.

\section{Review of the Literature}

Long a topic of debate for psychologists and lay people, personality theory, has evolved as human cognition, and child development research has progressed (Ford, 2013). Studies of personality type, especially among students, highlight the importance of understanding how the world is perceived and interfaced. Further, researchers may analyze the interactions of tasks, the environment, and potential actions of students for a given situation (Fretwell, Lewis, \& Hannay, 2013).

Also debated are learning theories and learning styles, of which there are as many definitions as there are researchers and ways to measure learning. In general, a learning style is a stable indicator of how the learner perceives, interacts with, and responds to an environment (Keefe, 1979). 


\section{The MBTI Instrument}

To assess the distribution of personality types among the students, the Myers-Briggs Type Indicator Form M (CPP, Inc., 2012) was used. The MBTI is based on the work of Jung's theory of psychological types (Myers \& McCaulley, 1985). Carl Jung, a student of Sigmund Freud, developed a theory of total personality utilizing four fundamental mental processes after disagreeing with Freud's stress on psychosexual development (Ryckman, 2013). The MBTI utilizes four dichotomies to reflect the preferences used by an individual to perceive the world and orient themselves appropriately (Myers \& McCaulley, 1985). The preferences affect what the individual focuses on in a given situation, as well as how they conclude the situation. The dichotomies come together to form 16 distinct personality types. Myers and McCaulley (1985) describe these traits as follows.

In type theory (Myers \& McCaulley, 1985), the attitude preference describes how an individual draws energy from their environment; extraversion (E) refers to energy drawn from the outer world, whereas introversion (I) refers to energy drawn from within an individual. Perception describes how a person becomes aware of their surroundings; sensing (S) perceivers use observational powers and a memory for details to establish what exists, while intuitive (N) perceivers use insight. The judgment preference describes the way a person draws conclusions about what they have perceived; those who think (T) use logical connections to bring together ideas, while those who feel (F) weigh relative values to come to a decision. The final dichotomy describes how an individual orients to the outer world through a perceptive $(\mathrm{P})$ attitude, attuned to incoming information and new experiences, or a judging $(\mathrm{J})$ attitude, preferring planning and organization.

The MBTI identifies the specific preferences of an individual to determine their personality type. Each dichotomy points in the direction of a preference; every person is assumed to use each of the four categories in some way, and the inventory identifies the strength of each preference (Myers \& McCaulley, 1985). The MBTI combines the preferences to create 16 personality types, as seen in the Sample Data Selection Ratio Type Table A1 in Appendix A1.

\section{The KLSI Instrument}

The experiential learning model is the foundation of the Kolb model and Kolb Learning Style Inventory (KLSI) (Kolb, 1984; Korn Ferry Hay Group, Inc., 2005). Experiential learning is a learning theory that assumes learning is influenced by the individual's accumulated experiences and must be adaptive. Kolb uses the 
experiential learning model to measure an individual's behavior throughout the learning process (Kolb, 1984). The Kolb model describes four stages of active learning and how an individual orients to a situation using his or her preferred learning method. The Kolb Learning Style Inventory (KLSI) assesses an individual's emphasis on each of the four stages of the learning process.

Concrete experience (CE) is often the first stage; this is when the learner encounters a new or reinterpreted experience (Kolb, 1984). The next stage is reflective observation ( $\mathrm{RO})$, in which the learner observes and reflects upon the experience. Abstract conceptualization (AC) is the next stage, in which reflection leads to new ideas or the modification of an abstract concept. Last, the learner participates in active experimentation (AE) by applying the experience and reflection to the surrounding world and observing the results. The theory stresses that effective learning will occur only when the learner passes through all four stages of the model (Kolb, 1984).

The Kolb model has four learning styles, or preferences, which are based on the stages of learning. The learning styles represent the patterns and consistencies within an individual's preferred learning process and are developed over time to various degrees.

The converger learning style is dominant in those who favor $\mathrm{AC}$ and $\mathrm{AE}$; this leaner utilizes deductive reasoning a practical approach to solving problems (Kolb, 1984). The diverger learning style favors CE and RO to make observations before organizing information and seek alternative solutions (Kolb, 1984). The assimilator learning style utilizes $\mathrm{AC}$ and $\mathrm{RO}$ utilize inductive reasoning to create theoretical models (Kolb, 1984). The accommodator emphasizes $\mathrm{CE}$ and AE to orient to changing environments and favors the intuitive approach (Kolb, 1984).

Although personality typing and identifying learning styles have faced criticism, both instruments have shown excellent reliability and validity (Coffield, Moseley, Hall, \& Ecclestone, 2004; Harker, Reynierse, \& Komisin, 1998; Myers \& McCaulley, 1985; Kolb, 1984) for studies in diverse fields (e.g., medicine, law, engineering, psychology, education, and management).

\section{The instruments in aviation studies}

Among college students, researchers have found that personality tends to stabilize through young adulthood, as many students must adapt to new surroundings and social norms while developing the fundamental aspects of their personality (Robins, Fraley, Roberts, \& Trzensniewski, 2001). Researchers have studied the personality types of professional pilots and military pilots using the 
Revised NEO Personality Inventory (NEO-PI-R) (Callister, 1999; Campbell, Castaneda, \& Pulos, 2009). However, the use of the MBTI in the field of aviation is limited (Kutz, Brown, Carmichael, \& Shandiz, 2004). Research analyzing the personality types of student pilots, and the implications thereof (e.g., academic success, attrition of types that do not have the "right stuff"), are even more limited.

The MBTI was used to assess the personality types of instructors, flight engineers, and commercial helicopter pilots and found the majority to fit the ESTP profile, or extrovert/sensing/thinking/perceiving profile (Tieger \& Barron-Tieger, 2001). Individuals with the ESTP type are characterized as enjoying the moment and adaptable; they make decisions through logical analysis and reasoning. Tieger and Barron-Tieger (2001) note that understanding personality type may guide career choices and impact job satisfaction. Devlin and Singh (2010) analyzed the MBTI personality types of 35 United States Air Force (USAF) officers and enlisted personnel in a hierarchical organization dissimilar to a college campus, yet the findings indicate similarities among those in a structured aviation environment. The study revealed a common type of introvert/sensing/thinking/judging (ISTJ, 20\%). The ISTJ individual is characterized as hardworking, practical, logical in approaching problems, and able to thrive in a structured organization such as the military. The MBTI personality types of 83 students enrolled in a university flight program were compared the results to the general population (Robertson \& Putnam, 2008). There was a statistically higher percentage of four personality types (ISTP, $12.1 \%$, ENTP, 9.6\%, INFP, 9.6\%, and INTJ, 7.2\%) relative to the general population, all of which are characterized as alert and quick to see patterns or possibilities (Myers \& McCaulley, 1985). Although the average characteristics of the sample align to predominant characteristics found in other studies, Robertson and Putman's (2008) findings did not reflect MBTI type distribution found by other studies using the MBTI.

Research utilizing other inventories and scales found similar characteristics among pilot groups. Using the NEO-PI-R, a personality inventory, Callister (1999) sampled 1,301 USAF student pilots and found them to be more extroverted, more assertive, and more competitive than the average person. Campbell et al. (2009) conducted a meta-analysis of studies using personality constructs in military aviation training and found low scores in neuroticism and high scores in extraversion, making the average military pilot better suited for stressful aviation training. It is important to note that both studies reported average characteristics for the samples and the generalization to other military groups and civilian student pilots was discouraged.

Although personality styles have been assessed, the learning styles of aviation students, and aviators in general is infrequently analyzed. The KLSI has 
been used in the military by Kanske (2001). The study found the convergent learning style to dominate 233 USAF pilots. These learners prefer to learn by doing an activity as opposed to being shown how to do the activity. The assimilative learning style was also typical among the pilots. These learners can create complex mental models using theory, concepts, and abstract ideas (Kanske, 2001). The KLSI was used in a longitudinal study focused on 420 aviation students (Kanske, Brewster, \& Fanjoy, 2003). The study found an overall significant deviation from population norms: predominant styles found in the study were convergers (34.4\%) and assimilators, favoring logic and systematic planning (32.8\%) (Kanske, Brewster, \& Fanjoy, 2003). Again, these studies focused on USAF pilots as opposed to collegiate student pilots, yet they provide an important comparison set. Gao, Au, Kwon, and Leong (2013) examined the learning styles of 88 students enrolled in a university aviation program and found the majority to be convergers or assimilators with a preference for abstract conceptualization. The study also considered the impact of culture on learning styles, which was not considered here.

The relationship of personality type and learning style indicates that although characteristics and preferences may shift with age, the inherent personality of an individual remains the same while orientation in a learning environment may be honed and developed. Jensen (2003) asserted that students could use MBTI results to understand how they approach learning. Kolb (1984) postulated that his model reflects Jung's (1921) type theory model, noting similarities between the KLSI preferences and the dichotomies. The learners described above may have a preference for theory and systematic planning when solving problems. In the aviation classroom, this can be translated to theory instruction, such as aerodynamics, and pre-flight planning to reinforce learning objectives (Gao et al., 2013). Although studies show that aviation students have similar learning styles, there are not enough studies to generalize about aviation students as a whole - most studies stressed that the findings might be limited to the study population.

\section{Participants}

\section{Method}

The population studied was aviation students enrolled in the aeronautical science degree program at Embry-Riddle Aeronautical University. The participants, who were contacted via email and announcements before class, selfselected to participate in the research study. To be eligible to participate, students must have completed their first solo flight. The sample size was 41 students, 31 males, 9 females, and one who did not identify gender. Stratifying participants according to class standing allowed comparison among type distribution; there 
were nine freshmen (22.0\%), 13 sophomores (31.7\%), eight juniors (19.5\%), and 11 seniors $(26.8 \%)$ in the sample. The average age of the students was 21 ( $S D=$ $1.5)$.

\section{Data Collection and Analysis}

This study utilized the MBTI Form M (CPP, Inc., 2012) to assess participant personality type and the KLSI Version 3.1 to examine participant learning style. Participants self-selected to participate in the research study. The MBTI Form M has 93 items, each of which has forced-choice responses of two options for determining personality type. The KSLI features 12 questions with rank ordered answers that correspond to the four learning stages (CE, RO, AC, AE), which is then mapped to learning style.

\section{Results}

\section{Personality Type Results}

Selection Ratio Type Tables (SRTTs) were created to compare distributions of the study samples to the distribution of a baseline sample of college students. Data were analyzed for the MBTI Form M using the four preference dichotomiesattitude (EI), perception (SN), judgment (TF), and orientation (JP). The SRTT utilizes a self-selection index $(I)$, generated by the Center for Applications of Psychological Type (CAPT) to compare the percentage of a sample distribution to a baseline sample for significance. An index $(I)$ of 1.0 and higher in the study sample means a higher percentage of the type for a college major than in the baseline sample. The prevailing MBTI type was ISTJ or introvert/sensing/thinking/judging; this type categorized 15 of the aviation students $(36.59 \%)$. The full distribution of the current study may be found in Appendix A1. The aviation students, assessed in the current study, were found to differ significantly from the distribution of personality types found in a traditional college major sample, as collected by Schaubhut \& Thompson (2011) $(N=108,699)$. The significantly over-represented dichotomies and types are highlighted in Table 1. Appendix A1 and A2 highlight Sample Data Selection Ratio Type Table and Sample Data Compared to College Baseline Selection Ratio Type Table.

To test attrition rate among the personality type by class standing (i.e., freshman, sophomore, junior, senior), the researcher ran a Pearson Chi-square test for independence in Statistical Package for the Social Sciences (SPSS; IBM Corp., 2013). The test showed no significant difference in type at the .05 level between the class standings, $\chi^{2}(39)=37.3, p=.55$. 
Table 1

Significant Differences between Aviation Students and College Major Sample

\begin{tabular}{lllllll} 
& $\begin{array}{l}\text { Aviation } \\
\text { Students } \\
n\end{array}$ & $\begin{array}{l}\text { Percent } \\
\text { of } \\
\text { Sample }\end{array}$ & $\begin{array}{l}\text { College } \\
\text { Major } \\
\text { Sample } n\end{array}$ & $\begin{array}{l}\text { Percent of } \\
\text { Sample }\end{array}$ & $\begin{array}{l}\text { Self- } \\
\text { select } \\
\text { Index }\end{array}$ & Sig. Level \\
\hline $\begin{array}{l}\text { Introvert } \\
\text { Sensing }\end{array}$ & 30 & $73.2 \%$ & 44,132 & $40.6 \%$ & 1.8 & $p<.001$ \\
$\begin{array}{l}\text { Thinking } \\
\text { ISTJ- }\end{array}$ & 30 & $85.4 \%$ & 60,545 & $55.7 \%$ & 1.5 & $p<.001$ \\
types & 15 & $73.2 \%$ & 47,828 & $44.0 \%$ & 1.7 & $p<.001$ \\
$\begin{array}{l}\text { ISTP- } \\
\text { types }\end{array}$ & 7 & $36.6 \%$ & 4,783 & $8.4 \%$ & 4.4 & $p<.001$ \\
\hline
\end{tabular}

Note. The inverse of the preference dichotomies was also significant at the same level (e.g., extroverts made up $26.83 \%$ of the study sample, significant at $p<.001$ ).

\section{Learning Style Results}

Using the KLSI Version 3.1, each student was characterized by one of four learning styles. In a normally distributed population, each learning style will be found in equal proportion (Kolb, 1984). Using a Chi-square goodness-of-fit test, the researcher analyzed the aviation student learning style distribution and found that the four learning styles were not equally distributed, $\chi^{2}(3)=7.4, p=.002$. Divergers were overrepresented in the sample $(n=17,41.5 \%)$ while assimilators $(n=10,24.4 \%)$ were normally distributed. Convergers $(n=7,17.1 \%)$ and accommodators $(n=6,14.6 \%)$ were below normal distribution amounts.

Because the means and distributions of the four KLSI learning stages of the sample and the normative sample for traditional college students $(N=10,423)$ (Kolb \& Kolb, 2013) were known, a $t$-test was used to analyze stratified data. Results for CE and RO were significant at $p<.001$. The average CE score for aviation students $(M=27.6, S D=9.9)$ was significantly different from the traditional college student score $(\mu=19.8, S D=6.5), t=5.0, p<.001$. A significant difference was found when comparing the average RO score for aviation students $(M=30.4, S D=6.8)$ to the traditional college student $(\mu=26.2, S D=7.0), t=3.9$, $p<.001$; Cohen's $d$ was computed to be 0.6 , considered to be a medium effect size. Table 2 demonstrates the differences between the study and the normative sample for traditional college students.

To test attrition rate among the learning styles by class standing (i.e., freshman, sophomore, junior, senior), the researcher ran a Pearson Chi-square test 
for independence in SPSS. The test showed no significant difference in learning style at the 0.05 level between the class standings, $\chi^{2}(9)=4.12, p=.90$.

Table 2

Differences between the Current Study and Normative Sample

\begin{tabular}{llllll} 
& $\begin{array}{l}\text { Study } \\
\text { Score } \\
M\end{array}$ & $\begin{array}{l}\text { Study } \\
\text { Score } \\
S D\end{array}$ & $\begin{array}{l}\text { Normative } \\
\text { Score } \\
\mu\end{array}$ & $\begin{array}{l}\text { Normative } \\
\text { Score } \\
S D\end{array}$ & $\begin{array}{l}\text { Significance } \\
\text { Level }\end{array}$ \\
\hline CE & 27.6 & 9.9 & 19.8 & 6.5 & $p<.001$ \\
RO & 30.4 & 6.8 & 26.2 & 7.0 & $p<.001$ \\
AC & 30.6 & 6.2 & 29.0 & 6.7 & $p=.01$ \\
AE & 31.3 & 9.2 & 31.8 & 5.9 & $p=.72$ \\
\hline
\end{tabular}

Note. The normative score refers to the normative sample for traditional college students (Kolb \& Kolb, 2013).

\section{Personality Type and Learning Style}

To determine if MBTI preference was correlated to learning style, betweensubjects ANOVAs were run using the continuous scores between each MBTI dichotomy (i.e., EI, SN, TF, JP) and the Kolb learning styles (i.e., accommodating, assimilating, converging, diverging). The alpha level was set at .05 for all tests. No significant relationship was found to indicate that personality preference and learning style are related. Pearson Chi-square test for independence analyses were run between the scores for each MBTI dichotomy and the scores of the four modes of the Kolb learning process (i.e., $\mathrm{CE}, \mathrm{RO}, \mathrm{AC}, \mathrm{AE}$ ). No significant relationship was found to indicate that personality preference predicted learning style. Table 3 displays the results of the analyses by MBTI preference dichotomy (row) and Kolb learning process (column).

\section{Discussion}

Understanding type theory and learning styles allows an educator to create a better learning environment while giving a student tools to enrich their learning experience (Felder \& Brent, 2005). The MBTI may be used to assess the personality type of an aviation student, providing information on focusing attention, information processing, decision-making, and orientation to the environment. The prevailing MBTI type of the sample had preferences of introverted, sensing, thinking, and judging, or ISTJ. People with this personality type are characterized as practical and systematic; they use logic and trust known, standard procedures to 
accomplish tasks (Myers \& McCauley, 1985). They may be more prone to trust the known processes and procedures they have used in training.

Table 3

Chi-Square Results of MBTI and KLSI

\begin{tabular}{lllllllll} 
& $\mathrm{RO}$ & & $\mathrm{CE}$ & & $\mathrm{AC}$ & \multicolumn{3}{c}{$\mathrm{AE}$} \\
& $\chi^{2}$ & $p$ & $\chi^{2}$ & $p$ & $\chi^{2}$ & $p$ & $\chi^{2}$ & $p$ \\
\hline EI Preference & .08 & .63 & -.08 & .60 & .10 & .51 & -.04 & .81 \\
SN & -.14 & .38 & -.16 & .31 & .10 & .52 & .21 & .19 \\
$\begin{array}{l}\text { Preference } \\
\text { TF }\end{array}$ & .21 & .19 & .13 & .44 & -.19 & .23 & -.16 & .32 \\
$\begin{array}{l}\text { Preference } \\
\text { JP Preference }\end{array}$ & -.12 & .45 & .07 & .65 & -.22 & .16 & .16 & .32 \\
\hline
\end{tabular}

The data revealed that the CE scores of 19 aviation students were in the $80^{\text {th }}$ percentile or higher when compared to population norms. Those who begin the learning cycle at the CE stage prefer to learn by being involved in an experience and working with feelings as opposed to theories. The scores of 16 aviation students were in the $80^{\text {th }}$ percentile or higher of the RO stage. These learners prefer to observe a situation, reflect on the meaning and implication thereof, and consider the perspective of others as well as their judgment before moving forward (Kolb, 1984).

The significantly high proportion of $\mathrm{CE}$ and $\mathrm{RO}$ orientation within the study aligns with the diverging learning style. These learners analyze concrete situations from many perspectives, observe their environment, and assess possible outcomes rather than merely reacting in a given situation (Kolb, 1984). This suggests that they rely on a balance of intuition, experience, and rote knowledge (e.g., emergency procedures in a flight). The students with this orientation may thrive when the curricula are less focused on theory in lecture-based instruction, and instead is more practical and hands-on with time for observation.

Although both studies took place at ERAU and assessed the personality types of aviation students, the results of this study differed from that of the Wiggins study (1998). Wiggins found an almost even split of introverts (55.79\%) and extroverts $(44.21 \%)$, whereas the sample data was much more differentiated (73.17\% introverts, $26.83 \%$ extroverts). Six personality types were overrepresented in the Wiggins (1998) sample, including ISTJ and ISTP. The study was more extensive and represented a higher proportion of students enrolled in the 
aeronautical science program at the time $(n=380,22.35 \%)$, and may provide more insight into the distribution within the program. Sample size notwithstanding, the prevalence of introverted, sensing students in significantly higher proportion in both samples supports other studies that found an overrepresentation of similar types. Appendix A3 details Sample Data Compared to Wiggins Sample Ratio Type Table.

\section{A Typical Student Pilot Profile}

Although statistical testing did not reveal a relationship between personality type and learning style in the present study, the dominant types were present in many of the students. When the characteristics of the prevailing personality type, learning styles, and general preferences associated with the types (i.e., ISTJ, diverging, $\mathrm{CE}$ and RO orientation) were reviewed, many similarities emerged. From these findings, a profile of aviation students can be created; the results suggest these students are observant of their surroundings and are able to adapt as situations change. They trust known procedures they have learned, especially when they have successfully used them or seen them in use. Aviation students prefer to use logical and objective methods to reach a solution as opposed to theories. To make decisions, the aviation students rely on their observations, their experience, and objective analysis to create a whole picture. There is a preference for hands-on learning and an appreciation of input from other people, both of which the student may draw from. These students are practical and analytical, preferring facts and the concrete over the theoretical. Finally, they work well with others, especially appreciating different perspectives to solve problems and achieve goals.

\section{Limitations}

The sample for this study was limited to aviation students enrolled in the aeronautical science baccalaureate degree program at Embry-Riddle Aeronautical University during the spring semester of 2017. To be eligible, the students must have completed a solo flight in their private pilot training. Similarities among this study, the Wiggins (1998) study, and others indicate that aviation students may embody characteristics and preferences that enable success in an aviation program. However, due to the nature and size of the sample, the results cannot be generalized beyond the study nor outside of the university. Further study would be required utilizing a larger student pilot sample, other degree programs, and other universities. 


\section{Recommendations and Conclusions}

Aviation students with the ISTJ personality can capitalize on their preference for sensing to gather information for future use and can utilize the thinking preference to make objective and logical choices (Myers \& McCaulley, 1985). Students with a preference for the diverging lifestyle may be more likely to succeed when learning is practical with opportunity for observation. Instruction for aviation students should include the discussion of situations, alternative solutions, and ensuring procedures become second nature so they may be relied upon in a dynamic environment. Scenario-based training is also vital for these learners to have a pool of experience to draw upon. The instinctual approach is often used for diverging learners, and they adapt well to situations that are unstructured (Kolb, 1984). When designing a course or learning experience for aviation students, an instructor should incorporate information on systems and procedures, should encourage discussion of past experiences so students may learn from their peers, and should engage students in practical exercises to strengthen skills.

Due to the limitations of this sample size which may prevent generalizing outside of the university population, the authors recommend for further research a replication of this study with a larger sample size, ideally engaging more than one institution. Flight students outside of formal higher education institutions may also be considered as participants. Finally, assessing educator and Certified Flight Instructor teaching style and personality type may reveal interesting information for structuring a professional pilot program to maximize learning and teaching efficiency. 


\section{References}

Callister, J. (1999). Revised NEO personality inventory profiles of male and female U.S. Air Force pilots. Military Medicine, 164(12), 885-890.

Campbell, J. S., Castaneda, M., \& Pulos, S. (2009): Meta-analysis of personality assessments as predictors of military aviation training success. The International Journal of Aviation Psychology, 20(1), 92-109. doi: http://dx.doi.org/10.1080/ 10508410903415872

Coffield, F., Moseley, D., Hall, E., \& Ecclestone, K. (2004). Learning styles and pedagogy in post-16 learning: A systematic and critical review. Retrieved from Learning \& Skills Research Centre, London: http://lerenleren.nu/bronnen/Learning\%20styles\%20by\%20Coffield\%20e. a..pdf.

CPP, Inc. (2012) Comparing the MBTI Form G \& Form M. Retrieved from https://www.cpp.com/ Pdfs/FormM_vs_FormG.pdf

Cronbach, L. J., \& Snow, R. E. (1969). Individual differences in learning ability as a function of instructional variables (Report No. Contract OEC 4-6061269-1217). Retrieved from http://eric.ed.gov/?id=ED029001

Devlin, M. S., \& Singh, A. (2010). MBTI personality and hemisphericity of a U.S. Air Force group. Leadership and Management in Engineering, 10(3), 108-120. doi: 10.1061/(ASCE)LM.19435630.0000063

Felder, R. M., \& Brent, R. (2005). Understanding student differences. Journal of Engineering Education, 94(1). doi:10.1002/j.2168-9830.2005.tb00829.x

Ford, M. (2013, August 5). A history of personality psychology: Part 1. Retrieved from http://blog.motivemetrics.com/A-History-of-Personality-PsychologyPart-1

Fretwell, C. E., Lewis, C. C., \& Hannay, M. (2013). Myers-Briggs type indicator, A/B personality types, and locus of control: Where do they intersect? American Journal of Management, 13(3), 57. 
Gao, Y., Au, K. T. S., Kwon, H. J., \& Leong, E. W. (2013). Learning styles of Australian aviation students: An assessment of the impact of culture. Collegiate Aviation Review, 31(1), 17-26. Retrieved from http://search.proquest.com.ezproxy.libproxy.db.erau.edu/docview/150261 0576 ? accountid $=27203$

Harker, J. B., Reynierse, J. H., \& Komisin, L. (1998). Independent observer ratings and the correlates of MBTI preferences with their behavioral descriptors. Journal of Psychological Type, 45.

IBM Corp. (2013.) IBM SPSS Statistics for Windows, Version 22.0. Armonk, NY: IBM Corp.

Jensen, G. H. (2003). Learning styles. In J. A. Provost \& S. Anchors (Eds.), Using the MBTI instrument in colleges and universities. Gainesville, FL: Center for Applications of Psychological Type.

Jung, C. G. (1921). Psychology of the unconscious: A study of the transformations and symbolisms of the libido; A contribution to the history of the evolution of thought. Moffat, Yard.

Kanske, C. A. (2001). Learning styles of pilots currently qualified in United States Air Force aircraft. Journal of Air Transportation World Wide, 6(2), 33-46.

Kanske, C. A., Brewster, L. T., \& Fanjoy, R. O. (2003). A longitudinal study of the learning styles of college aviation students. International Journal of Applied Aviation Sciences, 3(1), 79-89.

Keefe, J. W. (1979). "Learning style: An overview," in Student learning styles: Diagnosing and prescribing programs, Reston, Va.: National Association of Secondary School Principals, 1979.

Kolb, D. A. (1984). Experiential learning. Englewood Cliffs, New Jersey: Prentice Hall, Inc.

Kolb, D. A., \& Kolb, A. Y. (2013). The Kolb learning style inventory 4.0: A comprehensive guide to the theory, psychometrics, research on validity and educational applications. Boston: Hay Resources Direct.

Korn Ferry Hay Group, Inc. (2005). The cycle of learning (version 3.1) and learning-style type grid (version 3.1). Boston, MA: Resources Direct. 
Kutz, M. N, Brown, D. M., Carmichael, D. B., \& Shandiz, M. (2004). Preliminary implications for academic professionals of aviation student Myers-Briggs type indicator (MBTI) preferences. International Journal of Applied Aviation Sciences, 4(2), 221-228.

Myers, I. B., \& McCaulley, M. H. (1985). A guide to the development and use of the Myers-Briggs type indicator. Palo Alto, CA: Consulting Psychologists Press.

Robertson, M. F., \& Putnam, A. R. (2008). Personality types of student pilots admitted to the aviation flight program at Southern Illinois University Carbondale. Collegiate Aviation Review, 26(1), 111-124.

Robins, R. W., Fraley, R. C., Roberts, B. W., \& Trzesniewski, K. H. (2001). A longitudinal study of personality change in young adulthood. Journal of Personality, 69(4), 617-640.

Ryckman, R. (2013). Theories of Personality (10th ed.). San Francisco: Cengage Advantage Books.

Schaubhut, N. A., \& Thompson, R. C. (2011). MBTI type tables for college majors. Mountain View, CA: CPP, Inc.

Tieger, P. D. \& Barron-Tieger, B. (2001). Do what you are. Boston: Little, Brown \& Co.

Wiggins, M. E. (1998). Distribution of psychological types among students in a professional pilot baccalaureate degree program and associated attitudes towards teaching (Doctoral dissertation). Available from ProQuest Dissertations \& Theses Global. (Order No. 9930177). 


\section{Appendix A1}

Sample Data Selection Ratio Type Table

\begin{tabular}{lll} 
& \multicolumn{2}{l}{ Sample } \\
& Study \\
& $N$ & $\%$ \\
\hline ISTJ & 15 & 36.59 \\
ISFJ & 1 & 2.44 \\
INFJ & 1 & 2.44 \\
INTJ & 1 & 2.44 \\
ISTP & 7 & 17.07 \\
ISFP & 3 & 7.32 \\
INFP & 1 & 2.44 \\
INTP & 1 & 2.44 \\
ESTP & 2 & 4.88 \\
ESFP & 2 & 4.88 \\
ENFP & 0 & 0.00 \\
ENTP & 1 & 2.44 \\
ESTJ & 3 & 7.32 \\
ESFJ & 2 & 4.88 \\
ENFJ & 1 & 2.44 \\
ENTJ & 0 & 0.00 \\
\hline
\end{tabular}




\section{Appendix A2}

\section{Sample Data Compared to College Baseline Selection Ratio Type Table}

\begin{tabular}{llll}
\multicolumn{5}{c}{ Sample } \\
& Study & \\
& $N$ & $\%$ & $I$ \\
\hline ISTJ & 15 & 36.59 & $4.36 * * *$ \\
ISFJ & 1 & 2.44 & 0.35 \\
INFJ & 1 & 2.44 & 0.74 \\
INTJ & 1 & 2.44 & 0.90 \\
ISTP & 7 & 17.07 & $3.88 * * *$ \\
ISFP & 3 & 7.32 & 1.59 \\
INFP & 1 & 2.44 & 0.39 \\
INTP & 1 & 2.44 & 0.59 \\
ESTP & 2 & 4.88 & 0.77 \\
ESFP & 2 & 4.88 & 0.64 \\
ENFP & 0 & 0.00 & 0.00 \\
ENTP & 1 & 2.44 & 0.40 \\
ESTJ & 3 & 7.32 & 0.84 \\
ESFJ & 2 & 4.88 & 0.55 \\
ENFJ & 1 & 2.44 & 0.47 \\
ENTJ & 0 & 0.00 & 0.00 \\
\hline
\end{tabular}

Note. $I=$ self-selection index. $* * *=p<.001$. Sample data was compared to college baseline (Schaubhut, \& Thompson, 2011). 


\section{Appendix A3}

Sample Data Compared to Wiggins Sample Ratio Type Table

\begin{tabular}{llll}
\multicolumn{5}{c}{ Sample } \\
& Study & \\
& $N$ & $\%$ & $I$ \\
\hline ISTJ & 15 & 36.59 & $1.96^{* *}$ \\
ISFJ & 1 & 2.44 & 0.66 \\
INFJ & 1 & 2.44 & 2.32 \\
INTJ & 1 & 2.44 & 0.37 \\
ISTP & 7 & 17.07 & 1.85 \\
ISFP & 3 & 7.32 & 3.52 \\
INFP & 1 & 2.44 & 0.42 \\
INTP & 1 & 2.44 & 0.31 \\
ESTP & 2 & 4.88 & 0.64 \\
ESFP & 2 & 4.88 & 1.32 \\
ENFP & 0 & 0.00 & 0.00 \\
ENTP & 1 & 2.44 & 0.26 \\
ESTJ & 3 & 7.32 & 0.65 \\
ESFJ & 2 & 4.88 & 1.43 \\
ENFJ & 1 & 2.44 & 1.85 \\
ENTJ & 0 & 0.00 & 0.00 \\
\hline
\end{tabular}

Note. $I=$ self-selection index. $* *=p<.01$. Sample data was compared to data from the Wiggins (1998) study. 